revista ANTHROPOLÓGICAS

Ano 24, 31(2): 3-27, 2020

\title{
Antropologia da Infraestrutura no Brasil: Desafios teóricos e metodológicos em contextos emergentes
}

\author{
Alex Vailati ${ }^{\mathrm{a}}$ \\ Anthony D'Andrea ${ }^{b}$
}

\begin{abstract}
Este artigo discute a infraestrutura como tema emergente na antropologia brasileira. Embora já explicita em arenas públicas e midiáticas, a categoria esteve ausente da literatura antropológica nacional até recentemente. Inicialmente marginalizada enquanto um fenômeno estático e socialmente desinteressante, a infraestrutura foi redescoberta como formações simbólico-materiais dinâmicas interligadas em redes de fluxos diversos e epistêmicos de corte translocal. Este artigo, portanto, introduz uma coletânea de estudos etnográficos originais produzidos por pesquisadores baseados no Brasil, incluindo análises sobre infraestruturas de natureza industrial, residencial, cívica, digital, policial e contra-hegemônica. Em contextos interdisciplinares, este artigo sugere que infraestruturas podem ser examinadas através da tensão produtiva entre legados pós-coloniais e possibilidades cosmopolíticas, e, mais especificamente, considera que teorizações tópicas devem informar pesquisas etnográficas que, por sua vez, gerem conhecimentos de relevância nacional e intelectual.
\end{abstract}

Infraestrutura, Antropologia, Cosmopolítica, Colonialidade, Brasil.

\section{O paradoxo da infraestrutura}

Sob distintos pontos de vista, o uso contemporâneo da categoria infraestrutura tem conotações paradoxais. Juntamente com outras pa-

a Professor do Departamento de Antropologia e da Pós-graduação em Antropologia (UFPE). Email: alexvailati@gmail.com.

b Centro de Estudos Latino-Americanos, University of Chicago. Email: a-dandrea@uchicago.edu. 
lavras-chave que populam debates acadêmicos, políticos e populares, o termo tem definição vaga e relativa. $O$ paradoxo advém do fato desta categoria ter sido inicialmente teorizada em contextos analíticos que priorizavam a questão da desigualdade social, enquanto a infraestrutura é representada, notadamente dentro de contextos práticos, como solução ótima, universal e imparcial para diversos problemas, sejam técnicos, sociais ou ambientais. Contudo, trata-se de uma visão ideologicamente constituída devido aos efeitos de dominação e exploração, como evidenciados em movimentos sociais, indicadores econométricos e, mesmo, desastres ambientais imediatos.

Indicando um domínio material e analítico concernente a meios de produção articulados a esferas autorreprodutivas, a infraestrutura pode ser posicionada no entrecruzamento entre "três séries de condições sociais e materiais que permitem aos membros da sociedade produzir e reproduzir os requisitos materiais da sua existência social" (Godelier 1978:763). Estas incluem as condições ecológicas em que se encontra a sociedade; as forças produtivas que abarcam os meios materiais e intelectuais e as relações que permitem a produção e a redistribuição da mesma. Essa base contrapõe-se a esferas situadas além da infraestrutura, envolvendo sistemas políticos, culturais e ideológicos essenciais para a manutenção desses sistemas de produção. Não é nosso objetivo aqui o de percorrer em sentido genealógico todos os meandros intelectuais informando o tópico. Todavia, é importante trazer à tona alguns antecedentes que nos ajudam a entender os fundamentos epistêmicos do reconhecimento da infraestrutura enquanto categoria empírica e analítica.

Estes antecedentes iluminam o paradoxo das ideologias de infraestrutura no plano empírico e buscam repensar o que era até então percebido como uma dicotomia insuperável entre estruturalismos antropológicos e marxistas. Os esforços de Godelier, Sahlins e Clastres merecem menção como ponto de partida para uma antropologia da infraestrutura. Como inaugurador deste tipo de empreitada, Godelier traz o pensamento marxista para dentro da antropologia por meio 
do estruturalismo levistraussiano. Ele resgata o 'poder' das coisas (no sentido maussiano) para a análise de relações sociais em sociedades pré-capitalistas e capitalistas. Segundo ele, relações econômicas e políticas são tão importantes quanto a religião, a ideologia e o parentesco ao propulsionar processos de mudança em sociedades não capitalistas. Por outro lado, ele também percebe que as diferenças entre objetos modificados e presentes sociais tendem a desaparecer dentro de sociedades capitalistas (Godelier 1994), um processo a ser criticado conscientemente. Outra proposta crítica da divisão entre o material e o simbólico é objeto na reflexão de Marshall Sahlins, que problematiza essa fratura como resultado de um "gênero intelectual dicotômico" (Sahlins 1986:18). Falando de infraestruturalismo (Sahlins 2010) como um novo momento epistêmico, Sahlins questiona a falsa equivalência entre estruturalismo antropológico e superestrutura marxista. O campo da antropologia teria se voltado prevalentemente para a afirmação do estruturalismo que, na teoria marxista, é chamado de superestrutura (Sahlins 2010:372). Este posicionamento também é encontrado em Clastres, que integra categorias marxistas para demonstrar como as condições materiais podem ser estruturadas pela dimensão política. No caso extremo, a materialidade, entendida como esfera prevalentemente econômica, é a superestrutura que se torna possível somente através da preexistência de uma infraestrutura política (Clastres 1975). Não obstante posicionamentos substantivamente diferentes, estes autores questionam um tema fundamental da teoria antropológica: a guinada material ou infraestrutural. Se o prefixo 'infra' implicitamente indica algo que está abaixo e 'super' algo que ocupa uma posição superior, o nosso questionamento é como a dimensão material da vida social rearticula-se com outras esferas.

Não obstante estas contribuições embrionárias, reflexões sobre o estatuto antropológico da infraestrutura ficaram ausentes até recentemente, quando o tópico se desponta face à sua crescente popularização. A pesquisa de Susan Leigh Star é fundamental para entender o surgimento desse novo campo. Seu artigo foi aqui traduzido e dispo- 
nibilizado em função de seu pioneirismo no estudo de novas redes de comunicação relacionadas às tecnologias de informática. Para Star, a infraestrutura é um artefato cujo manuseio, ainda que formalmente documentado, raramente é problematizado em suas formas e informações, servindo assim de um espelho do mundo (Star 1999:388-389). Ela nota que as infraestruturas da informática são quase totalmente invisíveis, mas moldam a imaginação por meio de promessas otimistas sobre o futuro (Anand, Gupta \& Appel 2018). Em uma época dominada por entidades corporativas que alavancam capital por meio de macroestruturas transnacionais, a categoria vem crescentemente expressando-se a partir de meios de dominação, requerendo assim abordagens antropológicas sobre práticas, imaginários e efeitos de desigualdade que geram e pelos quais estão envoltas.

Como representam mais uma 'guinada' nas ciências sociais, vale considerar a diferença entre a emergente antropologia da infraestrutura a que nos referimos, em contraste a estudos antropológicos passados e mesmo recentes que envolvem infraestruturas de alguma forma, já há décadas. Até recentemente, antropólogos consideravam o estudo destas formações como inertes e desinteressantes, em geral servindo de pano de fundo para análises socioculturais localizadas e definidas prioritariamente (Di Nunzio 2018; Star 1999). Tal postura, entretanto, reflete representações modernistas que, inconscientemente afetando largos setores da academia, percebem infraestruturas dentro de visões funcionalistas técnicas não problematizadas. São representadas assim como soluções de eficácia prática e baixo significado simbólico, cujos efeitos são assumidos como largamente independentes das esferas de experiências vividas e políticas (Schmitt 2007).

Contudo, condições reflexivas e líquidas que emergem contemporaneamente contribuem para expor fraturas neste campo sociotecnológico, levando a uma revisão desses pressupostos modernistas e impulsionando uma conscientização mais problematizante do mesmo (Giddens 1989; Bauman 2000). Representações acadêmicas passam a vislumbrar e recortar um novo objeto, gradualmente reconhecendo a 
infraestrutura como vetor primário de organização da sociedade contemporânea (Scott 1998). Isso particularmente se reflete no caso brasileiro, onde infraestruturas destacam-se como marcas opulentas da ação governamental. Proporcionam assim um site analítico das práticas estatais e organizacionais convergentes com ideologias e processos de 'desenvolvimento' e globalização problemática. Evidentemente, esta nova antropologia expõe e examina consequências não previstas pelos próprios agentes produtores, resultando em efeitos acidentais por vezes contraditórios e deletérios (Rodgers \& O’Neill 2012). Infraestruturas possibilitam assim teorizar como processos amplos e abstratos - como Estado, cidadania, criminalidade, etnicidade e classe - manifestam-se concretamente em termos de práticas cotidianas.

\section{Localizando infraestruturas}

Uma das vertentes empiricamente mais ilustrativas e contemporâneas da antropologia da infraestrutura é o campo da tecnociência, como comumente explorado em estudos da ciência e tecnologia (STS). Segundo Larkin, no artigo traduzido e disponibilizado nesta coleção, essa linha analisa como infraestruturas mediam fluxos translocais, colocando pessoas, objetos e práticas em espaços de contato sob os quais modernos sistemas econômicos e sociais operam (Larkin 2013: 330). Além disso, infraestruturas permitem a criação de artefatos com formas específicas, os quais a análise antropológica pode explorar não só como representações do mundo, mas também como uma costura material e representacional (Larkin 2018).

A estética das infraestruturas é, nesse sentido, algo que antecede projetos políticos mais específicos. No Brasil, atores estatais e privados vêm articulando a formação de infraestruturas tecnocientíficas voltadas para a transferência de recursos e conhecimentos tecnológicos entre as ciências e a indústria. Em muitos casos, ilustram a emergência de "mercados tecnocientíficos", caracterizados pela "introdução de capital de risco e de novas relações entre governo, universida- 
de e indústria" (Fischer 2007:564, 2013; Rajan 2006). Em contextos nos quais discursos sobre a 'economia do conhecimento' tornam-se hegemônicos, 'inovação' e 'desenvolvimento' interligam-se como categorias chave de efeitos econômicos e ideológicos (Ferguson 1994; Olivier de Sardan 1995).

Estes novos cenários podem ser examinados a partir de duas questões fundamentais. Primeiramente, ainda que fixas, infraestruturas fundam-se em formas de mobilidade seletiva de artefatos, pessoas, práticas e capitais por meio de redes locais e globais de especialização. Tais fluxos inserem-se em regimes capitalistas neoliberais e desenvolvimentistas que se dão em contexto de globalização acelerada e desequilibrante. Infraestruturas assim promovem a concentração e a distribuição de recursos, ao mesmo tempo em que reinserem esses fluxos em arenas de aterrissagem organizadas em hierarquias múltiplas e frequentemente dispersas.

Além da questão das mobilidades, infraestruturas estão comumente envoltas em promessas tecnocráticas de 'neutralidade' e de 'desenvolvimento'. São formações que requerem investimentos pesados como condição possibilitadora da transferência de recursos e atividades geradoras de valor. Contudo, trata-se frequentemente de uma apropriação dupla, pois, em especial no caso brasileiro, investimentos infraestruturais são antecedidos por outra ordem de investimentos governamentais no campo da produção científica e educacional. Tais fluxos são então alavancados e mesmo apropriados pelo setor privado, frequentemente exacerbando situações de desigualdade e conflito. Aqui se manifesta, assim, o paradoxo da infraestrutura que abre este artigo.

Esses dilemas sociopolíticos e ideológicos atrelam infraestruturas emergentes a uma cacofonia de visões sobre o desenvolvimento, associadas a projetos de concentração neoliberal (frequentemente excludente) ou de participação democrática (supostamente inclusiva). Devido às inúmeras intervenções estatais em regiões menos desenvolvidas, infraestruturas configuram-se como tema estratégico do ponto 
de vista social e analítico. Ao relacionar ambos os predicamentos, o projeto antropológico é o de compreender a dinâmica sociopolítica e ideológica que confere (ou questiona) legitimidade a tais infraestruturas. Os objetos que as compõem em suas relações com humanos moldam a imaginação e a estética que se impõem a projetos políticos. Por outro lado, é possível observar o surgimento de reflexões contra processos políticos que visam a naturalizar a necessidade de tais entidades, de forma a destacar alternativamente outros projetos de teor contestatório (Bispo dos Santos 2015; Graeber 2004). foco deve, assim, centrar-se nos esforços, motivações e representações que dão sentidos diversos de legitimidade ou questionamento a tais processos interativos.

O exame destes predicamentos requer um tipo de engajamento analítico que integra uma sensibilidade cultural nuançada com uma abordagem etnográfica imersiva. $\mathrm{O}$ acesso físico a tais formações é frequentemente limitado, se não mesmo contencioso, pois o etnógrafo é geralmente alienígena a áreas de grande valor, risco ou contestação material (Mitchell 2013; Gusterson 1998). Por outro lado, espelhando a natureza dispersiva de infraestruturas modernas, deve-se considerar estratégias etnográficas multissituadas. Etnografias em instalações de alto risco ou segurança frequentemente só são possíveis às margens das mesmas (cafeterias de instalações, bares públicos, ou residências de atores especiais etc.). Como recomendação geral, o pesquisador de entidades complexas deve desenvolver metodologias multiescalares que incluem espaços interativos e decisórios, trajetórias e rivalidades individuais e coletivas, além de considerar como recursos materiais (financeiros e tecnológicos) são planejados, manuseados e aplicados em arenas de competição nacional e global. (Fischer 2013:382).

\section{Os desafios da colonialidade}

Ainda que adotando um enfoque empírico 'micro' de ator-rede, estudos antropológicos sobre formações infraestruturais frequente- 
mente remetem a debates entre perspectivas 'pós-coloniais' e 'cosmopolíticas' de desenvolvimento. Vale lembrar que esta dicotomia é típico-ideal, pois trata-se de perspectivas que contemplam uma variedade de nuances e recombinações. E, fundamentalmente a partir do Sul Global, a reflexão 'decolonial' também deve ser considerada dentro de uma antropologia da infraestrutura na região. Ao estabelecer estas pontes, busca-se explorar tensões produtivas entre um nativismo essencialista entrelaçado com inequidades estruturais e um internacionalismo otimista que emerge através de redes colaborativas transnacionais.

Dois obstáculos colocam-se à antropologia brasileira da infraestrutura. Inicialmente, a literatura tópica é dominada por enfoques instrumentais provenientes de ciências e profissões aplicadas (engenharia, administração e políticas públicas), priorizando processos de 'input-output' em níveis microeconômico, regional e nacional (Ades et al 2013; Centro de Apoio ao Desenvolvimento Tecnológico-MCTI 2013; Figlioli 2013; Gouveia 2013; Gouveia et al 2012; Querette et al 2010; Pereira \& Plonski 2009; Farias et al 2008; Ferreira 2008; Silva 2008; Rego 2006). Há alguma presença de estudos sociológicos sobre políticas de ciência e tecnologia, incluindo subtópicos como instituições de conhecimento, empreendedorismo e parcerias estatais (Arbix 2010; Balbachevsky \& Botelho 2011; Felizardo 2013; Guimarães 2011; Guimaraes \& Azambuja 2009; Monteiro, Campos, \& Dias 2014; Schwartzman 2008). Na antropologia da ciência e tecnologia brasileira, encontram-se estudos robustos sobre ontologias da natureza e do corpo (Monteiro 2012b, 2012c; Sautchuk 2007), assim como exames sobre a formação de epistemologias nativas forjadas em redes profissionais técnicas ou burocráticas (Lahsen 2004; Monteiro 2012a; Taddei 2013; D’Andrea 2010; Costa 2005). Há também alguns estudos etnográficos interessantes sobre a plataforma de lançamento astronáutico de Alcântara como objeto de debates desenvolvimentistas (Mitchell 2013); empresas de informática no Rio de Janeiro como site etnográfico para o estudo de práticas globalizadas (Takhteyev 2012); 
o Centro de Estudos do Petróleo de Campinas como foco de entendimento da interação entre universidade e empresa (Gielfi \& Pereira 2011); e o programa de caças da Força Aérea Brasileira como caso para o entendimento de obstáculos à transferência tecnológica na indústria militar (Peron 2011).

Muitos destes estudos alavancam abordagens fortemente influenciadas por teorias de ator-rede e linguagens do conhecimento (Callon 1980; Knorr-Cetina, Krohn \& Whitley 1980; Latour 1987, 2005). O foco geralmente reside em transposições de comandos, artefatos e recursos por meio de redes profissionais sustentadas por grandes instituições estatais, privadas e semipúblicas. Ainda que geralmente negligenciando o papel das infraestruturas como mobilizadoras e configuradoras de tais transposições, esta literatura explora como as normas cognitivas são compartilhadas através de relações interinstitucionais. Trata-se de terreno fértil para a análise da dinâmica de constituição de 'mundos de prática global' através dos quais 'objetos-conhecimento' gradualmente se normalizam em 'móveis imutáveis', que, assim, essencializam tais formações (Knorr-Cetina 1999, 2009; Latour 1987; Strathern 2014). Entretanto, tendo em vista os contextos de dependência econômica e tecnológica nos quais tais objetos de análise se inserem, pesquisadores frequentemente percebem 'a necessidade de integrar estas abordagens interacionistas com visões problematizantes das economias políticas que as condicionam' (Anderson 2009; Fischer 2007; Latour 1996).

Assim sendo, perspectivas pós-coloniais da infraestrutura buscam expor e examinar como os legados coloniais de dominação são amplificados por tais projetos desenvolvimentistas. A implantação de artefatos que afetam atores, local ou remotamente, permitem observar transposições assimétricas entre capital, conhecimento e propriedade, tanto histórica quanto geograficamente (Larkin 2013; Gunel 2011; Anand 2017; Anderson 2009; Biao 2006; Hetherington 2019; Lahsen 2004; Loomba, Kaul \& Bunzl 2005; Sassen 2006). Como classes dirigentes no Sul Global buscam transplantar tais modelos originados 
no Norte, é necessário considerar em que medida sociedades receptoras têm condições de absorvê-los reflexivamente, integrando componentes técnico-produtivos a tradições nativas, no sentido de gerar benefícios socialmente representativos (Fischer 2007:562; Jasanoff 2005; Pribilsky 2013).

Ademais, torna-se relevante decolonizar a infraestrutura, investigando como os atores conscientemente desafiam, reconfiguram ou se apropriam de seus elementos útil e significativamente (Anand 2017; Larkin 2004). Pirataria de produtos industriais e digitais, 'gatos' de água e eletricidade, adulterações em instrumentos de trabalho ou controle são alguns exemplos de mudanças inusitadas conduzidas nos propósitos e usos da infraestrutura, frequentemente consideradas ilícitas pelos poderes que as controlam. Decolonizar a infraestrutura é uma proposta que envolve também destacar concepções e práticas que se posicionam como epistemologias desafiadoras de um conhecimento técnico, que normalmente demanda legitimidade exclusiva (Bispo dos Santos 2015; Graeber 2004; Kopenawa \& Albert 2015; Krenak 2019).

\section{Promessas cosmopolíticas}

Por outro lado, apesar de seus efeitos imprevistos e negativos, infraestruturas também contribuem para uma visão cosmopolítica entendida como "terreno ou plateau ético que transforma o pensamento tradicional sobre o centro-periferia e as relações imperiais de poder" (Fischer 2007:576). Este modelo nos obriga a expor legados de dominação perpetuados através de sistemas de dependência, mas também a reconhecer casos de sucesso derivados de processos de colaboração transcultural (Baiardi \& Ribeiro 2011; Schwartzman 2008). Tais divergências se acentuam em contextos marcados pela "extensão de sistemas mundiais do capitalismo moderno e do colonialismo, assim como de novas redes que complicam o quadro de agentes nacionais e transnacionais, capital e trabalho" (Loomba et al 2005:17; Sassen 2007). Categorias geopolíticas são desestabilizadas, transformando e reinserindo formações locais dentro de hierarquias transnacionais. 
Neste processo, observa-se a reconfiguração de redes locais, nas quais conexões 'translocais' (nacionais e internacionais) tornam-se tão ou mais relevantes que as relações locais. Ambos os vetores cosmopolíticos e pós-coloniais alteram os fundamentos de governança e estruturação econômica e social, questionando assim a tese do nivelamento (flattening) global (Friedman 2007).

Os fluxos possibilitados por infraestruturas podem ser assim investigados a partir de duas considerações gerais. Primeiramente, processos de mobilidade constituem um espaço analítico interessante para explorar processos, efeitos e consequências relacionados às infraestruturas (Von Schnitzler 2013; D'Andrea et al 2011; Anderson 2009; de Laet \& Mol 2000; Urry 2007; Xiang \& Lindquist 2014). No caso de infraestruturas tecnocientíficas, como "práticas científicas são sempre multissituadas” (Anderson \& Adams 2007:184), o estudo da mobilidade - e da imobilidade - permite identificar, descrever e compreender câmbios, narrativas e redes que constituem zonas de contato que são possibilitadas pela infraestrutura. Esta abordagem revela como tais formações funcionam não somente como ferramenta ou símbolo de poder, mas também como arena de conflitos, desejos e intervenções (Larkin 2004; Larkin 2013; de Laet \& Mol 2000; Vailati $\&$ Zamorano no prelo; Von Schnitzler 2013). Apropriado ao entendimento destas formações emergentes no Brasil, o tema da mobilidade nos permite ver "como o conhecimento e prática formais se movem, e o que acontece aos mesmos nos pontos de chegada, e como se articulam dentro e através das culturas" (Anderson 2009:389).

Em segundo lugar, relacionado aos efeitos da mobilidade, a dimensão sociopolítica da infraestrutura é objeto de destaque nesta nova antropologia. Partindo do foco inicial em redes de prática profissional, pesquisadores estão mais recentemente voltando-se a questões de responsabilidade pública, governança e participação democrática (Larkin 2013; Von Schnitzler 2013; Hess 2007:464). Trata-se de um campo de análise interessante, tendo em vista que ideologias tecnocráticas tendem a ocultar efeitos de dominação, concentração e desi- 
gualdade sob um véu de 'neutralidade política' (Schmitt 2007 [1926]). Conflitos são assim delegados a um espaço administrativo que é representado como meritocrático, justo e imparcial, mas que frequentemente reproduz e amplifica formas de dominação e desigualdade crescentes (Fonte et al 2020; Amir 2012; Arendt 1998 [1958]; Masco 2006; Roszak 1995; Schmitt 2007 [1926]; Scott 1998). Assim sendo, antropólogos precisam "prestar atenção detalhada a epistemologias cívicas e culturas políticas, tornando-as mais reflexivas e inclusivas." (Fischer 2007:541; ver também Jasanoff 2005; Mathews 2008).

\section{Apresentando o dossiê}

As contribuições originais colocadas nesse número apresentam uma antropologia da infraestrutura emergente no Brasil, assim como a tradução para o português, de dois artigos clássicos. As obras inéditas tratam de tópicos de relevância contemporânea e já aqui aplicam, repensam e avançam elementos teóricos discutidos nesta introdução e nos artigos de Star e Larkin que aqui publicamos. Esta amostragem inclui análises etnográficas sobre efeitos temporais, excludentes e dominadores de infraestruturas industriais, digitais e neoliberais, assim como experiências e práticas de resistência e criatividade em relação às mesmas, como brevemente sumarizados a seguir.

Com foco na indústria siderúrgica no interior do estado do Rio de Janeiro, Maria Raquel Passos Lima examina a dimensão política e material da temporalidade. Infraestruturas geram promessas e constroem horizontes temporais repletos de possibilidades. A produção de resíduos tóxicos e a poluição ambiental são descritas não como consequências imprevistas da implantação industrial, mas como promessas que ganham visibilidade política ao longo de um horizonte temporal que se constitui a partir do seu estabelecimento. $\mathrm{O}$ artigo nos permite ver como a infraestrutura impõe aos sujeitos explorados, econômica e ambientalmente, um tempo fundado sobre a espera de realização de tais promessas. Se a mesma pode ser lida como resultante de uma política de governabilidade, a autora também destaca como 
sujeitos desenvolvem estratégias de resistência fundamentadas em sua resiliência. Esta contribuição permite repensar projetos exploratórios e coloniais de longo prazo, partindo da vitalidade de grupos sociais 'resistentes' na sociedade atual.

A dinâmica problemática da permanência é examinada por Yuri Rosa Neves, em sua análise etnográfica de um restaurante alternativo em Porto Alegre cuja fixação de preços é determinada pelos seus frequentadores. $\mathrm{O}$ dinheiro é aqui questionado como chave da infraestrutura comoditizada neoliberal. Não obstante ser elemento básico de grande parcela das interações urbanas, sua cotidianidade pode ser desvelada em momentos de crise. $\mathrm{O}$ ato de pagar, cuja banalidade não é percebida como parte de uma infraestrutura de matiz neoliberal, entra em colapso no caso analisado, mobilizando subjetividades a reagirem de forma reveladora. A ordinariedade da infraestrutura interiorizada é assim exposta por espaços imaginativos proponentes de uma agenda decolonial. Enquanto infraestruturas urbanas tornamse visíveis quando se quebram (e.g., blackout, falta d'água, greve de lixo etc.), a proposta de um restaurante sem preço evidencia um ato micropolítico que visa a educar, conscientizar e criar uma experiência específica consequente a práticas que implicitamente subvertem a infraestrutura econômica.

Efeitos sociais excludentes de infraestruturas residenciais de classe alta é o tema abordado no estudo de Rodrigo Agueda. Em uma etnografia conduzida no subúrbio da cidade do Rio de Janeiro, o autor observa como essas moradias se desenvolvem como empreendimentos modelados como condomínios-cidades enclausuradas ('gated communities'), social e espacialmente isolados do entorno urbano. Essa separação não somente constrange e controla a mobilidade de camadas populares, mas também bloqueia certos esforços do campo do analista. $\mathrm{O}$ artigo recorre à antropologia da infraestrutura para abordar o mundo das elites e da materialidade que as definem. A infraestrutura de condomínios, repleta de promessas de tranquilidade e de segurança, torna-se, segundo o autor, um indicador de desigual- 
dade urbana, demonstrando como falhas sistêmicas são fundantes do mesmo conceito de infraestrutura: neste sentido as insuficiências no sistema de segurança pública levam a rearticulação do espaço urbano a favor de elites sociais, em detrimento das necessidades de recursos pelas camadas populares.

Outras infraestruturas tendem a gerar mobilidades de forma mais dinâmica, como examinadas em duas contribuições focadas em casos de migração transnacional e transporte urbano. Anna Kurowicka examina o Centro Islâmico como espaço de alta circulação de migrantes oriundos do Sul Global na cidade do Recife. A infraestrutura constitui-se a partir de redes de relações articuladas por espaços físicos e por regimes legais que regulamentam a permanência de estrangeiros no país. A autora aborda as tensões entre agências cosmopolíticas que contestam racionalidades tecnoburocráticas estatais enquanto projetos de acolhimento despolitizantes. Assim, infraestruturas de migração duplamente possibilitam mobilidades e imobilidades, permitindo a seus sujeitos recriarem provisoriamente a mesma, repolitizando o espaço no qual circulam.

No estudo com motoristas do aplicativo Uber na cidade do Recife, Álvaro Tavares examina como esta plataforma modela a experiência urbana de motoristas e usuários por meio de algoritmos que remapeiam a mobilidade com finalidade de uso e lucro. Segundo o autor, enquanto o algoritmo tende a alienar os motoristas de sua relação experiencial com a cidade, pequenas falhas no aplicativo possibilitam práticas criativas resilientes. Ao demonstrar como humanos e não humanos interagem no substrato dessa infraestrutura digital de transporte, o artigo evidencia novas formas de agência que desafiam o controle e a soberania do mercado neoliberal de mobilidade na cidade.

A visibilidade de infraestruturas precárias é tópico de Helena Lancellotti, que examina sistemas, práticas e falhas do sistema eletrônico de vigilância penal no estado do Paraná. A tornozeleira eletrônica é o elemento portátil mais visível e mediatizado de uma complexa infraestrutura composta de artefatos físicos e sinais eletrônicos gerenciados 
por agentes e sujeitos de vigilância. Contudo, falhas frequentes levam essa infraestrutura a ser readaptada continuamente, revelando um paradoxo Kafkaesco: o sujeito portador da tornozeleira deve se assegurar do bom funcionamento da mesma para evitar o prolongamento da pena. As falhas sistêmicas e as estratégias dos atores colocam assim em xeque um sistema estatal apresentado como moderno e confiável.

Finalmente, visando a estimular o debate sobre a antropologia da infraestrutura no Brasil, esta coleção traz dois artigos clássicos traduzidos para o português. O artigo de Susan Leigh Star, originalmente publicado em 1990, pode ser considerado uma pedra angular desta literatura, propondo uma sistematização inicial que coloca a infraestrutura como categoria epistemológica autônoma. $\mathrm{O}$ contexto deste artigo se dá com a emergência de sistemas de informática virtuais e discretos, porém tão impactantes quanto infraestruturas massivas como classicamente imaginadas. $\mathrm{O}$ outro artigo traduzido é de autoria de Brian Larkin. Publicado em 2017, lança novos desafios para o estudo da infraestrutura, em função de um contexto em que redes digitais tornam-se indissoluvelmente ligadas à fábrica de cotidianidade local. Atualiza assim a proposta da Star, ao incorporar a literatura produzida nos últimos vinte anos. A materialidade, formas e promessas da infraestrutura são elementos centrais para a investigação de cunho político e poético da sociedade contemporânea.

\section{Notas para uma agenda de pesquisa}

Este dossiê visa contribuir para um debate crítico e informado pelas possibilidades empíricas e teóricas cotejadas nesta coleção, pondo em diálogo referências nacionais com estrangeiras. Este diálogo é considerado aqui como fundamental para o nosso fortalecimento, tendo em vista que as principais fontes de produção teórica e de pesquisa localizam-se no Norte Global. Nesse sentido, o dossiê proporciona uma primeira parada para refletir desafios no uso desta epistemologia, situando-a em campos empíricos e meios acadêmicos nacionais. Ademais, o conjunto dos artigos aqui apresentados visa a 
propor um mapeamento inicial das ricas possibilidades de pesquisa, apresentando um conjunto pequeno, porém diverso e representativo do espaço promissor de uma antropologia da infraestrutura no Brasil. Partindo dos artigos aqui apresentados, propomos a seguir reflexões indicando algumas possibilidades de pesquisa.

A heterogeneidade dos campos apresentados é uma primeira consideração que destacamos nesta coletânea, refletindo assim aspectos significativos de uma literatura tópica mais ampla. A infraestrutura confirma-se, então, como categoria transversal, cuja sofisticação epistemológica permite abordar objetos diferentes, como indústrias, recursos, migrações, assim como mobilidades espaciais, relações de classe e formas de controle e vigilância. Comum aos artigos desta coleção é a tensão implícita entre os projetos infraestruturais criados e impostos a diferentes sujeitos e as agendas conduzidas por estes em termos de intencionalidade e consequências não previstas, possibilitando assim vários caminhos de interpretação teórica por parte do analista.

O Estado, com forte papel desenvolvimentista e contraditório no espaço brasileiro, é claramente refletido nas análises aqui apresentadas. Como entidade complexa, permite e requer a análise matizada de seus vários aspectos, como a máquina burocrática, as ideologias desenvolvimentistas, as políticas de promoção ou regulamentação de mercados neoliberais e, em particular, um conjunto de práticas, agentes e consequências sociotécnicas que permite materializar. E este parece ser um ponto de grande originalidade em relação à produção antropológica brasileira, abordando o Estado como um problemático sistema de governabilidade e governança. Os artigos deste dossiê examinam a viabilização dos atores públicos local, regional e mesmo nacionalmente, focando empírica e conceitualmente nos loci onde se materializam. Estes olhares buscam destacar distintas associações onde a dimensão estética da presença do Estado, entendida aqui como algo percebido por meio de um conjunto sensorial, é contemporaneamente o resultado do seu impacto nas populações envolvidas e também o ponto de partida de sua ação. $\mathrm{O}$ dossiê permite, assim, abrir novos caminhos 
para exploração etnográfica destes espaços, deslindando a dimensão associativa que se desenvolve entre os atores humanos e não humanos envolvidos nesta trama.

A questão do espaço geográfico (social e físico), já saliente nesta coletânea, deve refletir aplicações relevantes da antropologia da infraestrutura no Brasil. Se esta consideração dá continuidade a literatura em geral, também evidencia futuras possibilidades de pesquisa. Isso tem a ver com a dimensão geográfica e histórica da infraestrutura. Em relação ao espaço, é possível afirmar que ainda há muitos contextos que poderiam ser analisados a partir da materialidade das infraestruturas que os permeiam. Pensamos aqui em contextos rurais ou semirrurais, que se distanciam implicitamente da modernidade urbana, na qual as diferenças étnicas e raciais são, na recente literatura, objeto de reflexão decolonial. Ademais, estruturas de grande porte, historicamente implantadas em espaços remotos, em função de processos de digitalização e miniaturização, vem gradualmente se localizando no entorno urbano (por exemplo, redes de inovação e energias alternativas que hoje frequentemente sobrepõem-se à cidade). São assim tipos de infraestrutura que se movem do rural ao urbano, e vice-versa. Uma antropologia da infraestrutura voltada à dimensão material e, consequentemente, estética, pode contribuir significativamente para este debate, destacando uma alteridade que se apresenta junto a específicas infraestruturas, diferenciadas daquela em decorrência da difusão global.

A dimensão política do tempo é outro tópico de reflexão empírica e epistemológica interessantemente abordada na antropologia da infraestrutura. Como as contribuições nesta coleção examinam, as temporalidades envolvidas em entidades infraestruturais moldam subjetividades e condicionam agências específicas, complementadas por metodologias de enfoque sincrônico, voltadas para o mapeamento de transformações em infraestruturas e suas conjunturas específicas. Neste sentido, como lacuna presente e necessidade para o enfrentamento em pesquisas futuras, a antropologia da infraestrutura 
deve ser mobilizada para analisar outros tempos, assim como outros espaços. Referimo-nos aqui a infraestruturas do Brasil pré-moderno: o desenvolvimento de sistemas produtivos extrativistas e mercantilistas, por exemplo, em canaviais e engenhos ligados a regimes coloniais e escravocratas, assim como o desenvolvimento precário de instituições imperiais transplantadas da Europa ao Brasil durante o século XIX, e esforcos desenvolvimentistas por regimes democraticos e militares no seculo passado. Uma visão infraestrutural sobre esta história provavelmente poderia abrir novos caminhos com pontos de vistas inéditos.

Inevitavelmente, estudos da infraestrutura devem considerar qual o estatuto dos processos de globalização, seja como horizonte de influência ou como tópico imediato de análise. Tendo em vista o caráter abstrato da globalização enquanto conceito, esse campo se desdobrou em duas grandes vertentes de fecundidade empírica e teórica: por um lado, processos de transnacionalidade e transnacionalismo, como predominantemente abordados na antropologia cultural, classicamente representada pelas reflexões de Arjun Appadurai; e, por outro, em processos de mobilidade, como referenciados na sociologia de sistemas complexos de John Urry. Em ambas as perspectivas, estudos sobre migração, transporte e turismo, assim como sobre distribuições fluídicas (vide os 'scapes' de Appadurai) têm provado uma rica base empírica sobre a qual a literatura relativa à globalização produtivamente se desenvolve. Como o olhar antropológico aproxima-se rapidamente do espaço tecnocientífico (e dos STS no plano analítico), tais formações são conformadas por processos transnacionais. No caso brasileiro, a investigação de infraestruturas emergentes de alta complexidade deve considerar fluxos e redes transnacionais que se dão no sentido Sul-Sul, Norte-Sul e Sul-Norte, incluindo o Mercosul e outros agentes ligados a nações desenvolvidas ou emergentes (China, Índia). Esses fluxos e redes frequentemente são partes essenciais conformadoras de infraestruturas que operam dentro de lógicas de acumulação neoliberal ou híbrida, materializando-se em espaços sociais urbanos e, cada vez mais, nos rurais. 
Finalmente, cabe mencionar a dificuldade metodológica para analisar entidades complexas e globalizadas, como é o caso de infraestruturas examinadas antropologicamente. A natureza dispersiva e, frequentemente, desterritorializada das mesmas e as dificuldades em cortar a rede em sentido stratherniano, forçam o pesquisador a considerar novas estratégias metodológicas que articulem adequadamente o plano de investigação empírica com o plano de validação conceitual e teórico. Metodologias multiescalares vêm sendo recomendadas já há algum tempo dentro da antropologia da globalização, mas se colocam ainda mais urgentes no caso de infraestruturas atreladas a cadeias translocais de fluxos de recursos de complexidade espacial, longitudinal e genealógica (Fischer 2013:382). Em outras palavras, a etnografia tem que cuidar em modo particular da dimensão escrita, para convincentemente justificar as descrições etnográficas em relação à teoria mobilizada ou pelas abordagens multimodais, que implicitamente priorizam a dimensão sensorial da etnografia, adotando eventualmente linguagens não escritas. De forma mais prática, essas metodologias devem considerar a possibilidade de focar a análise das infraestruturas por meio de um olhar aos espaços experienciais, considerando as interações e associações entre os atores, as redes envolvidas e as matérias e formas que tornam visível as infraestruturas, dentro de contextos regionais, nacionais e transnacionais.

\section{Referências:}

AMIR, S. 2012. The Technological State in Indonesia: The Co-constitution of High Technology and Authoritarian Politics. London: Routledge

ANAND, N. 2017. Hydraulic city: water and the infrastructures of citizenship in Mumbai. Durham: Duke University Press.

ANAND, N., GUPTA, A., \& APPEL, H. (eds.). 2018. The promise of infrastructure. Durham: Duke University Press.

ANDERSON, W. 2009. "From subjugated knowledge to conjugated subjects: science and globalisation, or postcolonial studies of science?". Postcolonial Studies, 124:389-400. 
APPADURAI, A. 1996. Modernity at Large: Cultural Dimensions of Globalization. Minneapolis: University of Minnesota Press.

ARBIX, G. 2010. "Innovation and the Development Agenda". Economic Sociology, 112:16-23.

ARENDT, H. 1998. The Human Condition. Chicago: University of Chicago Press.

BAIARDI, A., \& RIBEIRO, M. C. 2011. "A cooperação internacional norte-sul na ciência e tecnologia: gênese e evolução". Caderno CRCH, 24(63):593-608.

BALBACHEVSKY, E., \& BOTELHO, A. 2011. Science and Innovation policies in Brazil: a framework for the analysis of change and continuity. Trabalho apresentado no "IPSA-ECPR: Whatever Happened to North-South?", USP, Sâo Paulo-SP.

BAUMAN, Z. 2000. Liquid Modernity. Cambridge: Polity Press.

BIAO, X. 2006. Global 'Body Shopping': An Indian Labor System in the Information Technology Industry. Princeton: Princeton University Press.

BISPO DOS SANTOS, A. 2015. Colonização, Quilombos modos e significados. Brasília: Universidade de Brasília.

CALLON, M. 1980. "Struggles and Negotiations to Define What is Problematic and What is Not: The Socio-logic of Translation". In KNORR-CETINA, K. (ed.): The Social Process of Scientific Investigation, pp. 197-221. Dordrecht/ Boston: Reidel.

CENTRO DE APOIO AO DESENVOLVIMENTO TECNOLÓGICO - MCTI. 2013. Estudos de Projeto de Alta Complexidade: indicadores de parques tecnológicos.

CLASTRES, P. 2017. A sociedade contra o estado. São Paulo: Editora Ubu.

COSTA Jr, L. C. 2005. Reflexividade e Aceleração: Estratégias Racionais de Sobrevivência - o caso dos profissionais do pólo de informática do Recife. Dissertação de Mestrado. Recife: Universidade Federal de Pernambuco.

CRUZ, R. 2004. O Que as Empresas Podem Fazer pela Inclusão Digital. São Paulo: Instituto Ethos de Empresas e Responsabilidade Social.

D'ANDREA, A. 2010. 'You Shouldn't Take the BlackBerry to your Bedroom': Mobility and Flexibility among High-Tech Workers of the National Technology Park Ireland. Field Report: University of Limerick.

D'ANDREA, A., GRAY, B., \& CIOLFI, L. (eds.). 2011. "Methodological Challenges and Innovations for Mobilities Research". Mobilities Journal, 6(2): 149-160.

DE BOECK, F., \& BALOJI, S. 2016. Suturing the city: living together in Congo's urban worlds. London: Autograph ABP.

DE LAET, M., \& Mol, A. 2000. "The Zimbabwe Bush Pump: Mechanics of a Fluid Technology”. Social Studies of Science, 30(2):225-263.

DI NUNZIO, Marco 2018. 'Anthropology of Infrastructure'. Governing Infrastructures Interfaces - Research Note. London: London School of Economics and Political Science. 
FARIAS JR, I. et al. 2008. "Porto Digital: Um Exemplo de Responsabilidade Social”. Novas Tecnologias na Educação, 6(2):1-10.

FELIZARDO, R. 2013. Em Busca de Novos Padrões de Desenvolvimento: Os Parques Tecnológicos no Brasil. Dissertação de Mestrado. São Paulo: Universidade de São Paulo.

FERGUSON, J. 1994. The Anti-Politics Machine: 'Development', Depoliticization, and Bureaucratic Power in Lesotho. Minneapolis: University of Minnesota Press.

FERREIRA, L. 2008. Estudo Comparativo de Arranjos e Sistemas Produtivos Locais de Software no Nordeste do Brasil. Rio de Janeiro: Universidade Federal do Rio de Janeiro.

FIGLIOLI, A. 2013. Em Busca da Sustentabilidade Econômico-Financeira de Organizações Gestoras de Parques Tecnológicos: Proposta de Modelo de Negócio no Contexto Brasileiro. Tese de Doutorado, São Paulo: USP.

FISCHER, M. 2007. "Four Genealogies for a Recombinant Anthropology of Science and Technology". Cultural Anthropology, 224(*):539-615.

FISCHER, M. 2013. "Biopolis: Asian Science in the Global Circuitry". Science Technology E Society, 18(3):379-404.

FONTE, C., PORTELA, L. \& JESUS, M. 2020. Território Suape. Vídeo Documentário.

FRIEDMAN, T. 2007. The World is Flat 3.0: A Brief History of the Twenty-First Century. New York: Picador.

GIDDENS, Anthony 1989. The Consequences of Modernity. Stanford: Stanford University Press.

GIELFI, G., \& PEREIRA, N. 2011. "A Unicamp e a indústria de petróleo: uma análise da produção científica do Centro de Estudos do Petróleo". In MONTEIRO, M., CÁMPOS, C. \& DIAS, R. (eds.): Novos Horizontes em Politica Cientifica e Tecnológica, pp. 15-36. Santo André: UFABC.

GODELIER, M. et al. 1978. "Infrastructures, Societies, and History". Current Anthropology, 19(4):763-771.

GODELIER, M. 1994. "Deconstruct to Reconstruct: An Interview with Maurice Godelier, by Paul Eiss and Thomas Wolfe". The Journal of the International Institute. (https://quod.lib.umich.edu/j/jii/4750978.0001.207/--deconstructto-reconstruct-an-interview-with-maurice? $r g n=$ main;view=fulltext; acesso em 30/11/2020).

GOUVEIA, C. 2013. Porto Leve - A Mobility and Safety Intelligent Infrastructure Urban Solution for Porto Digital. Trabalho apresentado no "30th IASP World Conference on Science and Technology". Recife-PE.

GOUVEIA, C., TARGINO, P., \& SABOYA, F. 2012. Porto Digital's Support System for Economic Development and Innovation Promotion. Trabalho apresentado no "29th IASP World Conference". Tallin, Estonia.

GRAHAM, S., \& MCFARLANE, C. Eds.. 2015. Infrastructural lives: urban infrastructure in context. London: Routledge, Taylor \& Francis Group. 
GRAEBER, D. 2004. Fragments of an anarchist anthropology. Chicago: Prickly Paradigm Press.

GUIMARÃES, S. 2011. "Produção do Conhecimento Científico e Inovação: desafios do novo padrão de desenvolvimento". Caderno CRCH, 24(63):461-466.

GUIMARÃES, S., \& AZAMBUJA, L. 2009. "Empreendedorismo high-tech no Brasil: Condicionantes econômicos, políticos e culturais”. Revista Sociedade e Estado, 25(1):93-121.

GUNEL, G. 2011. "Spaceship in the Desert: Conceptions of Abu Dhabi's Masdar City". Anthropology News, Out.:3-4.

GUSTERSON, H. 1998. Nuclear Rites: a Weapons Laboratory at the End of the Cold War. Berkeley: University of California Press.

HESS, D. J. 2007. "Crosscurrents: Social Movements and the Anthropology of Science and Technology". American Anthropologist, 109(3):463-472.

HETHERINGTON, K. (ed.). 2019. Infrastructure, environment, and life in the Anthropocene. Durham: Duke University Press.

JASANOFF, S. 2005. Designs on Nature: Science and Democracy in Europe and the United States. Princeton: Princeton University.

KNORR-CETINA, K. 1999. Epistemic Cultures: How the Sciences Make Knowledge. Cambridge: H. U. Press.

2009. "The Synthetic Situation: Interactionism for a Global World". Symbolic Interactionism, 32(1):61-87.

KNORR-CETINA, K., KROHN, R. \& WHITLEY, R. (eds.). 1980. The Social Process of Scientific Investigation. Dordrecht/Boston: Reidel.

KOPENAWA, D. \& ALBERT. B. 2015. Queda Do Céu: Palavras de Um Xamã Yanomami. São Paulo: Companhia das Letras.

KRENAK, Ailton. 2019. Ideias Para Adiar o Fim Do Mundo. São Paulo: Companhia das Letras.

LAHSEN, M. 2004. "Transnational Locals: Brazilian Experiences of the Climate Regime”. In JASANOFF, S. \& MARTELLO, M. (eds.): Earthly Politics: Local and Global in Environmental Governance, pp. 151-172. Boston: MIT.

LARKIN, B. 2004. "Degraded Images, Distorted Sounds: Nigerian Video and the Infrastructure of Piracy”. Public Culture, 16(2):289-314. . 2013. "The Politics and Poetics of Infrastructure". Annual Review of Anthropology, 42:327-343. . 2018. "Promising Forms: The Political Aesthetics of Infrastructure". In ANAND, N., GUPTA, A., \& APPEL, H. (eds.): The promise of infrastructure, pp.175-202 Durham: Duke University Press.

LATOUR, B. 1987. Science in Action: How to Follow Scientists and Engineers Through Society. Milton Keynes: Open University Press. . 1996. "The Trouble with Actor Network Theory". Soziale Welt, 47:369-381. 2005. Reassembling the Social: An Introduction to Actor Network Theory.

Oxford: Oxford University Press. 
LOOMBA, A., KAUL, S., \& BUNZL, M. 2005. Postcolonial Studies and Beyond. Durham: Duke University Press.

MASCO, J. 2006. The Nuclear Borderlands: The Manhattan Project in Post-Cold War New Mexico. Princeton: Princeton University Press.

MATHEWS, A. S. 2008. "State Making, Knowledge, and Ignorance: Translation and Concealment in Mexican Forestry Institutions". American Anthropologist, 110(4):484-494.

MITCHELL, S. T. 2013. "Space, Sovereignty, Inequality: Interpreting the Explosion of Brazil's VLS Rocket". The Journal of Latin American and Caribbean Anthropology, 18(3):395-412.

MONTEIRO, M. 2012a. "Imagens de Satélite como Sítio Etnográfico? Interpretando práticas de sensoriamento remoto no Brasil”. In KERBAUY, T., ANDRADE, T. \& HAYASHI, C. (eds.): Ciência, Tecnologia e Sociedade no Brasil, pp. 251-278. Campinas: Alinea. . 2012b. Os Dilemas do Humano: reinventando o corpo numa era biotecnológica. São Paulo: Annablume. . 2012c. "Reconsiderando a Etnografia da Ciência e da Tecnologia: Tecnociência na prática”. Revista Brasileira de Ciências Sociais, 277(9):139-232.

MONTEIRO, M., CAMPOS, C., \& DIAS, R. (eds.) 2014. Novos Horizontes em Politica Cientifica e Tecnológica. Santo Andre: Universidade Federal do ABC.

OLIVIER DE SARDAN, Jean-Pierre. 2005 Anthropology and Development: Understanding Contemporary Social Change. London: Zed Books.

PEREIRA, L., \& PLONSKI, G. 2009. "Shedding light on technological development in Brazil". Technovation, 29:451-464.

PERON, A. 2011. A factibilidade da transferência de tecnologia e o spinoff no Programa FX-2 da FAB 59. In MONTEIRO, M., CAMPOS, C., \& DIAS, R. (eds.): Novos Horizontes em Política Cientifica e Tecnológica, pp. 59-74. Santo André: UFABC.

PLONSKI, G. 2005. “Bases para um Movimento pela Inovação Tecnológica no Brasil". São Paulo em Perspectiva, 19(1):25-33.

PRIBILSKY, J. 2013. "Technoscience in Las Américas: STS Engagements in Latin American Anthropology". The Journal of Latin American and Caribbean Anthropology, 18(3):371-375.

QUERETTE, E., SABOYA, F., \& MOLINA, A. 2010. Porto Digital: a model of implementing a Technology Park as a driver for economic development. Trabalho apresentado no "XXVII IASP World Conference on Science and Technology". Daejeon, Coreia do Sul.

RAJAN, K. 2006. Biocapital: The Constitution of Postgenomic Life. Durham: Duke University Press.

REGO, I. M. 2006. "A Cidade Virtual: O Porto Digital como representação do Recife". Iniciacom, 1(1):1-10.

RODGERS, D. \& O'NEILL, B. 2012. "Infrastrutural violence: Introduction to the special issue”. Ethnography, 13(4):401-412 
ROSZAK, T. 1995. The Making of a Counterculture: Reflections on the Technocratic Society and its Youthful Opposition. Berkeley: Univ. of California.

SAHLINS, M. 2010. "Infrastructuralism”. Critical Inquiry, 363(*):371-385.

SASSEN, S. 2006. Cities in a World Economy. Thousand Oaks: Pine Forge. (ed.). 2007. Deciphering the Global: Its Scales, Spaces and Subjects. New York: Routledge.

SAUTCHUK, C. 2007. "A medida da gordura: o interno e o íntimo na academia de ginástica”. Mana, 13(1):153-179.

SCHMITT, C. 2007 [1926]. "The Age of Neutralizations and Depoliticizations". In SCHMITT, C. et al. (eds.): The Concept of the Political, Expanded Edition, pp. 80-96. Chicago: Chicago University Press.

SCHWARTZMAN, S. (ed.) 2008. Universidad y Desarrollo en Latinoamérica: experiencias exitosas de centros de investigación. Bogotá: UNESCO-IESALC.

SCOTT, J. C. 1998. Seeing Like a State: How Certain Schemes to Improve the Human Condition Have Failed. New Haven: Yale Univ. Press.

SILVA, F. Q. B. 2008. A City and its Science Park: building a local innovation system for urban and economic development. Trabalho apresentado no "XXV IASP World Conference on Science and Technology". Johannesburg, Africa do Sul.

STAR, S. L. 1999a. "The Ethnography of Infrastructure”. American Behavioral Scientist, 43(3):377-391.

STEWART, K. 2007. Ordinary Affects. Durham: Duke University Press.

STRATHERN, M. 2014. O Efeito Etnográfico e Outros Ensaios. São Paulo: Cosac \& Naify.

TADDEI, R. 2013. "Anthropologies of the Future: On the Social Performativity of Climate Forecasts”. In KOPNINA, H. \& SHOREMAN-OUIMET, E. (eds.): Environmental Anthropology: Future Directions, pp.244-263. London: Routledge.

TAKHTEYEV, Y. 2012. Coding Places: Software Practice in a South American City. Massachusetts: MIT Press.

URRY, J. 2007. Mobilities. Cambridge: Polity Press.

VAILATI, A. \& ZAMORANO, G. (eds.). (no prelo). Ethnographies of 'On Demand' Films: Anthropological Explorations of Commissioned Audiovisual Productions. New York: Palgrave.

VON SCHNITZLER, A. 2013. "Traveling Technologies: Infrastructure, Ethical Regimes, and the Materiality of Politics in South Africa”. Cultural Anthropology, 28(4):670-693.

XIANG, B., \& LINDQUIST, J. 2014. "Migration Infrastructure”. International Migration Review, 48(1):122-148.

Abstract: This article discusses infrastructure as an emerging topic in Brazilian anthropology. While prominent in public and media spaces, the category has been largely absent from national anthropology until recently. Ini- 
tially sidelined as static and socially uninteresting composites, the notion of infrastructure has been rediscovered in relation to dynamic symbolic-material formations entwined with various flows and epistemic networks at local and translocal levels. This article therefore introduces a number of original ethnographic studies authored by researchers in Brazil, including studies on industrial, residential, social, digital, surveillance, and counter-hegemonic infrastructures. Moreover, this dossier includes translations of two classic texts in the international anthropology of infrastructure. Within broader interdisciplinary contexts, this article suggests that infrastructures can be examined across the productive tension between postcolonial legacies and cosmopolitical possibilities, and, more specifically, considers that topical theorizations should inform local ethnographic research which, in turn, can generate new knowledge that is nationally and intellectually relevant.

Keywords: Infrastructure, Anthropology, Cosmopolitics, Colonialism, Brazil.

Recebido em novembro de 2020.

Aprovado em dezembro de 2020. 